DOI: 10.14451/1.173.83

\title{
АНТИМОНОПОЛЬНЫЙ КОМПЛАЕНС, КАК ФАКТОР РАЗВИТИЯ ИННОВАЦИОННОГО ПОТЕНЦИАЛА ПРЕДПРИНИМАТЕЛЬСКИХ СТРУКТУР
}

\section{(c) 2019 Плетешков Александр Николаевич}

аспирант

Санкт-Петербургский университет технологий управления и экономики, Россия, Санкт-Петербург

E-mail: axenus@bk.ru

В статье рассматриваются проблемы формирования инновационного потенциала предпринимательских структур. Идентифицирована сущность антимонопольного комплаенса, как одного из инструментов, предоставляемых предпринимательским структурам государством для развития их инновационного потенциала и повышения эффективности функционирования.

Ключевые слова: предпринимательство; инновационный потенциал; антимонопольный комплаенс, экономическая эффективность, антимонопольное законодательство, конкуренция

В последние годы значительное развитие получила тема инновационного предпринимательства, где внимание уделяется не просто традиционному предпринимательству, но с использованием инструментов инновационного развития. В то же время, несмотря на рост активности в этой сфере (хотя именно в области исследования инноваций наблюдается определенный спад, вызванный тем, что при всей видимости инновационной активности, результаты не соответствуют усилиям), наблюдается весьма низкий уровень инновационной активности предприятий (рис.1) [12].
Инновационная активность в области технологических инноваций, определяющих темы и вектор научно-технического прогресса, находится на одном уровне (и даже с падением) уже в течение ряда лет. Причин для подобной ситуации достаточно, но основная -отсутствие у большинства предприятий условий для реализации этой формы деятельности, низкая восприимчивость к инновациям и даже их отторжение. Т.е., бизнес и инновации существуют не во взаимодействии, но даже в противоречии друг к другу.

Действительно, даже в условиях значитель-

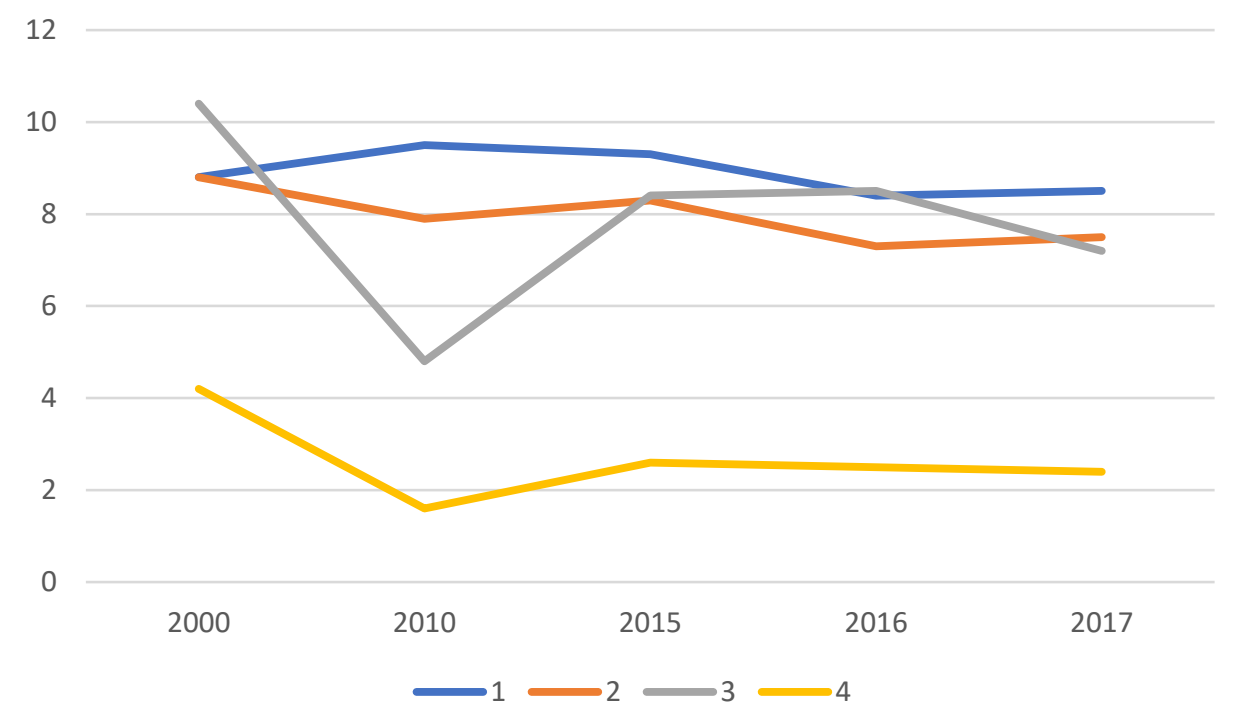

Рис.1 Динамика показателей инновационной деятельности в РФ.

1- инновационная активность организаций (удельный вес организаций, осуществлявших технологические, организационные, маркетинговые инновации, в общем числе обследованных организаций),\%;2-удельный вес организаций, осуществлявших технологические инновации, в общем числе обследованных организаций, процентов; 3 - удельный вес инновационных товаров, работ, услуг в общем объеме отгруженных товаров, выполненных работ, услуг,\%; 4-удельный вес затрат на технологические инновации, в общем объеме отгруженных товаров, выполненных работ, услуг,\%. 
ной роли государства в российской экономике (доля его варьируется по различным источникам от 50 до 80\%), предпринимательство должно сыграть определенную роль в условиях перехода к инновационному типу развития. В частности, Й. Шумпетер, выдвинул тезис что предприниматели являются основными драйверами производства, обмена и распределения в условиях рынка, а само по себе новаторство в деятельности предпринимателя - источник общего движения [17]. Понятие «предпринимательская структура» предполагает «обособленную, гибкую к изменению внешних условий структуру экономической системы, характеризующуюся устойчивостью, инновационностью, стратегической нацеленностью, конкурентоспособностью, покупательской направленностью, элементами которой являются подразделения или отдельные участники, основная цель которых - получение прибыли в результате использования имущества, продажи товаров, оказания услуг, ведения работ» [5]. Само же развитие предпринимательской структуры является результатом внешних и внутренних изменений, одновременно являясь субъектом этих изменений.

Предпринимательская структура действует не в безвоздушном пространстве, а взаимодействует со всеми акторами предпринимательского процесса в целях получения и удержания конкурентного преимущества, что предполагает обеспечение ее соответствующей ресурсной базой, составляющие которой, в частности, входят в предпринимательский потенциал. Потенциал предпринимательских структур, определяется, в первую очередь, наличием соответствующих ресурсов, хотя при этом идет постоянная путаница понятий - «ресурсы предпринимательской структуры», «ресурсы предпринимательства», «предпринимательские ресурсы» и т.п. Есть еще «ресурсы предпринимательской деятельности фирмы». Все-таки, мы будем говорить о совокупности ресурсов предпринимательской структуры, которые в простейшем виде могут быть представлены как: финансовые (основной и оборотный капитал); производственные; имущественные; трудовые; информационные; интеллектуальные; пространственные; временные и т.п. Возвращаясь к инновациям, согласимся с тем, что «инновация - это нововведение, повышающее социально-экономическую эффективность производства в любой сфере деятельности предприятия: в технике, технологии, организа- ции труда, условиях труда, управлении». Тогда, в простейшем варианте, инновационный потенциал представляет собой определенные возможности предпринимательских структур, связанные с разработкой и реализацией нововведений (в том числе из внешней среды), направленных на его системную техническую, управленческую и организационную модернизацию.

В настоящей статье используется терминологический аппарат, который на протяжении десятилетий складывался в отечественной экономической науке. При этом следует отметить, что за последние годы он был обновлен в гораздо большей степени, чем за все предшествующие десятилетия своего формирования. Более того, многие понятия, традиционно в нем используемые, получили новое прочтение, стали интерпретироваться совсем по-новому. Связано это с тем, что в условиях санкций, сделавших актуальной переориентацию экономики на импортозамещение и импортоопережение, в стратегических и комментирующих их документах акцент оказался смещен на понятия, которые если и не были раньше совсем маргинальными, то находились на периферии внимания российских экономистов. Сейчас определение «инновационный» начинает применяться ко многим терминам, которые десятилетиями существовали без него. Про «инновационный потенциал» можно сказать, что это как раз классический случай такого создания нового термина. В новом экономическом контексте это соединение двух традиционных терминов в один, и достаточно частое (может быть излишне) его использование позволяет предположить, что компоненты приобрели несвойственные им ранее значения и дополнительные смыслы.

В настоящее время вопрос эффективности новых технологий, управленческих решений, новой продукции сомнению в актуальности не подвергается. Инновационный характер позволяет отличить нововведения от открытий и изобретений с учетом практической ценности. Там, где заканчивает свой процесс изобретатель, начинает предприниматель, управляющий инновационным процессом: в его руках новый товар или новая технология начинают приносить выгоду. Управление инновационным потенциалом всегда включает процесс реализации, который находится между точкой создания чего-то нового и той, где это новое становится источником прибыли. 
Для предпринимателей этот процесс всегда связан и с перераспределением прибыли с целью вложения средств в новое, позволяющее ускорить экономический рост. Поскольку в современных условиях ни один из видов бизнес-процессов не может реализовываться без определенного (не обязательно прямого) финансирования одно из современных определений «инновации», учитывает это и звучит следующим образом: «Под инновацией (англ. innovation - нововведение, новаторство) мы понимаем «инвестицию в новацию» как результат практического освоения нового процесса, продукта или услуги. Новация (лат. novation - изменение, обновление) представляет собой какое-то новшество, которого не было раньше: новое явление, открытие, изобретение, новый метод удовлетворения общественных потребностей и т.п. Инновация представляет собой материализованный результат, полученный от вложения капитала в новые продукты или технологию, в новые формы организации производства труда, обслуживания, управления и т.п.» [10].

Теоретический аспект темы инноваций связан не только с вопросом об их возможных типах, но и том, что может побудить предпринимателей рискнуть и вообще попытаться запустить инновационный механизм. Независимо от того, предполагается ли выход на новые рынки или появилась возможность обойти конкурентов, запуск инновационных процессов обязательно для них повлечет за собой процесс изменений. Поэтому именно «изменение» современные экономисты выделяют как основную функцию «инновации» как экономической категории. Изменения могут носить разный характер в зависимости от того, что будет основным объектом нововведений и обновлений. Так И. Шумпетер [17], выделяет следующие типы инновационных изменений: использование новых технологий и оборудования, выпуск новой продукции, нововведения в организации производства, появление новых рынков сбыта, использование нового сырья, вызываемых именно «рыночной конкуренцией». Соответственно, выигрыш в конкуренции обеспечивается функциями инноваций, обеспечивающих развитие предпринимательской структуры:

- «воспроизводственная;
- инвестиционная;
• стимулирующая» [10].
Каждая из них связана с инновационным потенциалом, предпринимательской структуры, имеющей дополнительный источник дохода от внедрения инноваций - от эксплуатации ее финансовых возможностей для внедрения новых инноваций до финансовой поддержки других перспективных в плане получения прибыли проектов, в том числе внедрения организационноэкономических инноваций

Таким образом, в современной российской экономической системе и в протекающих в рамках ее хозяйственных процессах, инновации имеют свое логически обоснованное место. Последнее подкрепляется тем, что у них есть свой определённый функционал, основой которого является экономическое развитие предпринимательских структур, для получения дополнительной прибыли и новых рынков. Конечно, в каждом отдельном случае функции инноваций могут различаться, в зависимости от того, как именно инновационный потенциал владельцы предпринимательских структур в данный момент решают использовать, тем не менее в основе этого процесса всегда будет лежать коммерциализация каких-либо нововведений и изобретений.

Методические подходы к определению понятия «инновационный потенциал» предпринимательской структуры, подразделяются на (табл.1): ресурсный; результатный; внутренний, внешний, причем первые три являются традиционными, последний же подход возникает, на наш взгляд, не только вследствие изменения внешней среды (в том числе в инновационной сфере), но и вследствие действий государства, устанавливающего новые «правила игры».

Таким образом, можно утверждать, что формирование инновационного потенциала предпринимательской структуры может и, во многом, осуществляется за счет внешних факторов, в частности, управленческих решений принимаемых на уровне законодательных и других нормативных актов.

Естественно, что речь идет не о преимуществах в том или ином виде, предоставляемых нормативными актами обязательного исполнения, но лишь о тех, которые предоставляют предпринимательской структуре определенные преференции, связанные с добровольным использованием соответствующих нормативных актов.

В качестве примера возможно привести использование положений антимонопольного 
Таблица 1. Методические подходы к формированию понятия «инновационный потенциал»

\begin{tabular}{|c|c|c|}
\hline $\begin{array}{c}\text { Методический } \\
\text { подход }\end{array}$ & Сущностные признаки подхода & Содержание понятия \\
\hline Ресурсный & $\begin{array}{l}\text { - предполагает наличие неиспользуемых в настоящее время } \\
\text { совокупных ресурсов, которые могут быть привлечены для повы- } \\
\text { шения инновационной активности и достижения инновацион- } \\
\text { ных целей предпринимательских структур; } \\
\text { - инновационный потенциал рассматривается как возмож- } \\
\text { ность, не реализуемая в настоящее время; } \\
\text { - количественная и структурная совокупность ресурсов опреде- } \\
\text { ляет возможности развития инновационного потенциала. }\end{array}$ & $\begin{array}{l}\text { совокупность имею- } \\
\text { щихся у предприни- } \\
\text { мательской струк- } \\
\text { туры ресурсов для } \\
\text { реализации иннова- } \\
\text { ционного развития } \\
\text { структуры }\end{array}$ \\
\hline Результатный & $\begin{array}{l}\text { - совокупность инновационных ресурсов, представленных в } \\
\text { виде продукта инновационной деятельности в производствен- } \\
\text { ной сфере[7]; } \\
\text { - внутренняя возможность инновационной структуры осущест- } \\
\text { влять целенаправленную деятельность по привлечению конкрет- } \\
\text { ных ресурсов и их эффективной трансформации для формирова- } \\
\text { ния инновационного продукта; } \\
\text { - способность предпринимательской структуры создавать но- } \\
\text { вую стоимость путем привлечения всех его имеющихся (и воз- } \\
\text { можных для привлечения со стороны) материальных и немате- } \\
\text { риальных активов с целью его инновационного развития [6]; } \\
\text { результативная составляющая выступает отражением конечного } \\
\text { результата реализации имеющихся возможностей (в виде нового } \\
\text { продукта, полученного в ходе осуществления инновационного } \\
\text { процесса (например, использования технологических иннова- } \\
\text { ций) [13]. }\end{array}$ & $\begin{array}{l}\text { способность пред- } \\
\text { принимательской } \\
\text { структуры формиро- } \\
\text { вать и обеспечивать } \\
\text { результаты иннова- } \\
\text { ционной деятельно- } \\
\text { сти. }\end{array}$ \\
\hline $\begin{array}{l}\text { На основе исполь- } \\
\text { зования факторов } \\
\text { внутренней среды } \\
\text { предпринима- } \\
\text { тельской струк- } \\
\text { туры }\end{array}$ & $\begin{array}{l}\text { - объективные факторы внутренней среды инновационного } \\
\text { потенциала определяют его количественные параметры, спо- } \\
\text { собность инициировать, распространять инновации, привлекать } \\
\text { ресурсы на принципах коммерческой результативности; } \\
\text { - субъективные факторы инновационного потенциала проявля- } \\
\text { ются в процессе принятия и реализации управленческих реше- } \\
\text { ний, относящихся к инновациям }\end{array}$ & $\begin{array}{l}\text { способность эффек- } \\
\text { тивно преобразовы- } \\
\text { вать ресурсы пред- } \\
\text { принимательской } \\
\text { структуры в иннова- } \\
\text { ционный продукт. }\end{array}$ \\
\hline $\begin{array}{l}\text { На основе исполь- } \\
\text { зования внешних } \\
\text { факторов }\end{array}$ & $\begin{array}{l}\text { - объективные факторы внешней среды инновационного по- } \\
\text { тенциала (например, мировые тенденции развития технологий } \\
\text { в сфере деятельности предпринимательской структуры, измене- } \\
\text { ние структуры рынка потребления продукции предприниматель- } \\
\text { ской структуры и др.); } \\
\text { - субъективные факторы внешней среды инновационного по- } \\
\text { тенциала проявляются в процессе принятия и реализации управ- } \\
\text { ленческих решений, относящихся к инновациям, на которые } \\
\text { предпринимательская структура влиять не может (в частности, } \\
\text { можно говорить, как о инновационных решениях формирования } \\
\text { инновационного потенциала предпринимательской структуры, } \\
\text { законодательных и других нормативных актов государственных } \\
\text { и надгосударственных структур }\end{array}$ & $\begin{array}{l}\text { Способность гибко } \\
\text { реагировать на изме- } \\
\text { нения в нормативных } \\
\text { ми законодательных } \\
\text { актов, используя их } \\
\text { для развития иннова- } \\
\text { ционного потенциала } \\
\text { предприниматель- } \\
\text { ской структуры }\end{array}$ \\
\hline
\end{tabular}

На основе: Кочетков С.В. Регулирование и инструментарий развития инновационного потенциала единицы хозяйствования. Дисс.д-ра экон.наук. СПб.: СПбГУЭФ. 2009. С. 78.

комплаенса, как предоставляющего (на определенных условиях) преференции предпринимательским структурам при нарушении ими антимонопольного законодательства. Известно, что в законопроекте «О внесении изменений в Федеральный закон «О защите конкуренции» и Кодекс Российской Федерации об административных правонарушениях», вводится понятие «антимонопольный комплаенс», трактуемое как «система внутреннего обеспечения соответствия требованиям антимонопольного законо- дательства (антимонопольный комплаенс) - совокупность правовых и организационных мер, предусмотренных внутренним актом (актами) хозяйствующего субъекта либо другого лица из числа лиц, входящих в одну группу лиц с таким хозяйствующим субъектом, если такие внутренние акты распространяются на такого хозяйствующего субъекта, и направленных на соблюдение им требований антимонопольного законодательства и предупреждение его нарушения» [18], то есть, если говорить более простым языком - 
это наличие у предпринимательской структуры (хозяйствующего субъекта) соответствующей внутренней системы, препятствующей нарушению антимонопольного законодательства, минимизации антимонопольных рисков что, в свою очередь, ведет к снижению уровня связанных с этим соответствующих антимонопольных санкций.

Правовое обеспечение использование рычагов комплаенса, с одной стороны, для обеспечения соблюдения антимонопольного законодательства, с другой, - для повышения уровня благосостояния фирм, заинтересованных в защите свободы конкуренции, уже длительно (с 2013 года) обсуждается предпринимателями и представителями ФАС России с 2013 года. При этом мы наблюдаем один из немногих случаев, когда практика опережает теорию: системы менеджмента качества, независимая оценка деятельности компаний, направленной на снижение рисков нарушения антимонопольного законодательства, уже получили широкое распространение, хотя и не под вывеской «комплаенса».

Комплаенс, впервые возникнув, как вынужденная система мер защиты от действий соответствующих надзорных служб, в последнее время стал осознаваться предпринимателями, как реальный механизм старта инновационных процессов, жизненно необходимый самим предпринимательским структурам. Вопрос не в том, требуют или не требуют, и кто требует введения антимонопольного комплаенса: предпринимательские структуры предприниматели начали отслеживать и, по возможности ликвидировать, нарушения антимонопольного законодательства до фиксации их соответствующими органами. В процессе функционирования комплаенссистем в предпринимательских структурах, возникает, кроме предупреждения конкретных нарушений, связанных с антимонопольным законодательством, так называемый вторичный эффект за счет устранения недостатков в работе других функциональных систем. Последнее связано с тем, что в основе комплаенса лежит управление кадровым потенциалом структуры, работа с персоналом, формирование здорового делового климата и культуры реализации всей коммерческой деятельности. Установлено, что, если приоритетом деятельности сотрудников становятся этические принципы, может быть снижен риск возникновения должностных преступлений, разглашения коммерческих тайн и коррупционной составляющей.

Таким образом, использование предпринимательскими структурами антимонопольного комплаенса можно идентифицировать как наращивание инновационного потенциала, что в конечном итоге, влечет за собой предотвращение или снижение финансовых потерь, связанных с санкциями соответствующих государственных органов в рамках антимонопольной деятельности; снижение вероятности задействования коррупционных схем и других подобного рода угроз бизнесу; сохранение деловой репутации компаний и, в конечном счете, повышение их конкурентоспособности и инвестиционной привлекательности.

\section{Библиографический список}

1. Алешин M.М., Алешина Е.И. Комплаенс как инструмент повышения стоимости корпорации // Интернетжурнал «НАУКОВЕДЕНИЕ» Том 8, № 5 (2016) http://naukovedenie.ru/PDF/48EVN516.pdf.

2. Антимонопольный комплаенс: текущая практика и перспективы развития. Аналитический доклад Центра при Правительстве Российской федерации. декабрь 2015. ac.gov.ru.

3. Антимонопольный комплааенс в компаниях потребительского сектора. 3 февраля 2016 года. http://hvglaw. nl/Publication/vwLUAssets/ey-antitrust-compliance-mining/\$FILE/ey-antitrust-compliance-mining.pdf.

4. Андрей Цыганов о внедрении антимонопольного комплаенса. 22 апреля 2016 года. https://fas.gov.ru/ news $/ 4164$

5. Герасимова Е.А. Развитие инновационного потенциала предпринимательской структуры, как фактора повышения конкурентоспособности// Проблемы современной экономики, 2011.

6. Иващенко С.M., Рушев А.Д. Сущность и структура инновационного потенциала организации / С. М. Иващенко, А.Д. Рушев [Электронный ресурс] Режим доступа: http://vfmgiu-trade.ru/Avtorskie_stati/SUShhNOST_I_ STRUKTURA_INNOVACIONNOGO_POTENCIALA_ORGANIZACII/index.html.

7. асатая И.Л. Экономическое содержание и особенности инновационного потенциала /Вестник Челябинского государственного университета, 2009, № 2 (140), Экономика, вып.18. С. 5-13

8. . Еереминская. Освобождение от проверок ФАС как награда за введение комплаенса. https://www.vedomosti. ru/economics/articles/2017/04/19/686315-osvobozhdenie-ot-proverok 
9. Михненко Т.Н. Влияние антимонопольного комплаенса на эффективность функционирования хозяйствующих субъектов и экономики в целом // Интернет-журнал «Мир науки» 2015 № 2 http://mirnauki.com/ PDF/09KMN215.pdf.

10. Основы инновационного проектирования: учебное пособие / Кипчарская Е.В., Сергеев В.А., Подымало Д.К. и др.- Ульяновск: Ул ГТУ.-С. 9.

11. Политика Группы компаний «Норильский Никель» в области антимонопольного комплаенса. https://www. nornickel.ru/files/ru/corporate_documents/policies/Antitrust-Compliance_Policy_201017-ru.pdf.

12. Российский статистический ежегодник, 2018. М.: Росстат, 2018. - с. 493

13. Сивов М.В. Сущность и основные элементы инновационного потенциала региона // Молодой ученый.2016. - № 11. - C. 984-987. - URL https://moluch.ru/archive/115/30836/ (дата обращения: 01.05.2019).

14. Тимошкин А.В. Экономическая эффективность комплаенс-контроля// «Банковское дело» N7-2012 г.

15. ФАС предлагает новую обязанность для госкомпаний - проверку антимонопольных рисков https://www. vedomosti.ru/economics/articles/2016/07/01/647547-fas-predlagaet-novuyu-obyazannost-dlya-goskompanii

16. Федеральный закон от 26.07.2006 N135-Ф3 (ред. от 29.07.2017) «О защите конкуренции».

17. Шумпетер Й.А. Теория экономического развития. М.: Прогресс, 1982. С. 177-178.

18. http://regulation.gov.ru/projects/List/AdvancedSearch\#npa=50178 